\title{
Experimental and Numerical Study of Carbon-Dioxide Dissociation for Mars Atmospheric Entry
}

\author{
X. Lin* \\ State Key Laboratory of High-Temperature Gas Dynamics, Institute of Mechanics, Chinese \\ Academy of Sciences, 100190 Beijing, People's Republic of China \\ L. Z. Chen \\ China Academy of Aerospace Aerodynamics, 100074 Beijing, People's Republic of China \\ and \\ J. P. Li, F. Li,,$\stackrel{\S}{=}$ and X. L. YuI \\ State Key Laboratory of High-Temperature Gas Dynamics, Institute of Mechanics, Chinese \\ Academy of Sciences, 100190 Beijing, People's Republic of China
}

DOI: $10.2514 / 1 . T 5152$

\begin{abstract}
The mechanism of $\mathrm{CO}_{2}$ dissociation during entry in the Mars atmosphere is experimentally investigated. A hydrogen-oxygen combustion-driven shock tube is used to simulate physical and chemical conditions in a $\mathrm{CO}_{2}-\mathrm{N}_{2}$ mixture. Two shock velocity/initial pressure conditions are studied: $7.09 \pm 0.05 \mathrm{~km} / \mathrm{s}$ at $100 \mathrm{~Pa}$ (called the low-pressure condition) and $5.68 \pm 0.07 \mathrm{~km} / \mathrm{s}$ at $300 \mathrm{~Pa}$ (called the high-pressure condition). The temperature behind the shock wave is obtained by analyzing the high-temporal-resolution and high-spatial-resolution experimental spectra of the $\mathrm{CN}$ violet $\left(B^{2} \Sigma^{+} \rightarrow X^{2} \Sigma^{+}, \Delta v=0\right)$ system. The $\mathrm{CO}$ number density is derived using a tunable diode laser absorption spectroscopy system based on $\mathrm{CO}$ absorption near $2.33 \mu \mathrm{m}$. Moreover, a numerical code is developed to reproduce the experimental results (temperatures and species densities). The kinetic code in this work is based on Park's two-temperature model. Comparisons between experiments and calculations are presented. Such a relatively simple two-temperature model fails to accurately describe the nonequilibrium temperature and $\mathrm{CO}$ number density but is suitable for equilibrium temperature predictions.
\end{abstract}

\section{Introduction}

$\mathbf{M}$ ARS is one of the most attractive and ambitious objectives for future manned space exploration. In previous unmanned missions, radiation has not been a concern in the design of the thermal protection system. The radiative heat flux accounts only for a few percent of the total heat flux, owing to a combination of moderate entry velocities and small vehicle sizes [1]. However, future Mars exploration systems, especially those in support of crewed missions, will be larger landers and have higher-speed entries. Radiative heating, which can be comparable to or even greater than convective heating, will make an important contribution to the entry heating environment [2] (e.g., radiation is predicted to contribute at least $80 \%$ of the total heat flux at velocities over $8.5 \mathrm{~km} / \mathrm{s}$ [3]). As we know, the radiation intensity strongly depends on physical and chemical phenomena occurring in the shock layer in front of the heat shield of a space probe.

The Martian atmosphere consists of $95.7 \% \mathrm{CO}_{2}, 2.7 \% \mathrm{~N}_{2}$, and $1.6 \% \mathrm{Ar}$ [4]. The main radiators in these conditions are $\mathrm{C}_{2} \mathrm{Swan}$ bands, the $\mathrm{CN}$ red system, the $\mathrm{CN}$ violet system, and especially the $\mathrm{CO}$ fourth positive system, which is predicted to be the dominant source of shocklayer radiation during future Mars entries []]. The dissociation of $\mathrm{CO}_{2}$ is one of the most important reactions because it directly affects the

Received 7 December 2016; revision received 12 October 2017; accepted for publication 13 October 2017; published online 16 November 2017. Copyright $\odot 2017$ by the American Institute of Aeronautics and Astronautics, Inc. All rights reserved. All requests for copying and permission to reprint should be submitted to CCC at www.copyright.com; employ the ISSN 0887-8722 (print) or 1533-6808 (online) to initiate your request. See also AIAA Rights and Permissions www.aiaa.org/randp.

*Senior Engineer, No. 15 Beisihuanxi Road; currently China Academy of Aerospace Aerodynamics, 100074 Beijing, PRC; linxin_bit@163.com.

${ }^{\dagger}$ Professor, Beijing Key Laboratory of Arc Plasma Application Equipment, No. 17 West Yungang Road; quarter724@ sohu.com.

¥Associate Professor, No. 15 Beisihuanxi Road; jinping.li@foxmail.com.

${ }^{\S}$ Associate Professor, No. 15 Beisihuanxi Road; Lifei@imech.ac.cn.

Professor, No. 15 Beisihuanxi Road; currently School of Engineering Science, University of Chinese Academy of Sciences, 100049 Beijing, PRC; xlyu@imech.ac.cn (Corresponding Author). rates of all chemical reactions, it affects the radiative flux generated by species, and the dissociation products $(\mathrm{CO}, \mathrm{O})$ considerably affect the heat flux on the heat shield via catalytic recombination reactions [ $\underline{6}-\underline{8}]$. Although the chemical kinetics in the shock layer has been extensively studied, the mechanism of $\mathrm{CO}_{2}$ dissociation under conditions relevant to Mars entry is not well understood. Therefore, to further study physical and chemical phenomena in the shock layer and accurately predict the aerothermal heating environment for upcoming demanding missions, more detailed experimental and numerical research on the mechanism of $\mathrm{CO}_{2}$ dissociation during entry is required.

The physical and chemical processes in a shock layer are usually studied in a shock tube or a shock tunnel, the conditions of which are the closest possible to the real conditions of entry into the planetary atmosphere. Different groups from the United States, Russia, Australia, Japan, and Europe have performed a number of shock-tube radiation experiments for Mars entry employing optical emission spectroscopy (OES) [ㅁ-13]. OES is a well-known nonintrusive diagnostic technique that has been widely used for studying chemical reactions and measuring absolute radiation. A radiative heating experiment, for example, was conducted at the NASA Ames Research Center on the electric arc shock tube with a $96 \% \mathrm{CO}_{2}$ and $4 \% \mathrm{~N}_{2}$ gas mixture at 0.1 torr (13.3 Pa) initial pressure and $8.5 \mathrm{~km} / \mathrm{s}$ shock velocity [1]. This was the first quantitative spectrograph measurement of the $\overline{\mathrm{CO}}$ fourth positive system in conditions relevant to Mars atmospheric entry. Meanwhile, valuable experiments were carried out at the University of Provence on the TCM2 free-piston shock tube with different mixtures: $70 \% \mathrm{CO}-30 \% \mathrm{~N}_{2}$, $70 \% \mathrm{CO}_{2}-30 \% \mathrm{~N}_{2}$, and pure $\mathrm{CO}_{2}[\underline{6}, \underline{13}, 14]$. In those studies, the relationship between the nonequilibrium radiation and shock velocity and that between the nonequilibrium radiation and initial pressure of the test gas were analyzed. Simultaneously, thermodynamic parameters, such as rotational temperature $T_{r}$ and vibrational temperature $T_{v}$, were acquired through a comparison of the observed spectra with theoretical ones.

In parallel, several kinetic models have been established to reconstruct the preceding experiments and provide insight into the chemical kinetics and nonequilibrium radiation occurring in the shock layer. In 1984, for example, Park proposed a two-temperature model for kinetic calculation [15]. Later, the theory was completed 
and improved to develop more detailed models, such as threetemperature models and collisional-radiative models [16,17]. However, many questions on chemical reaction modeling, especially on dissociation and even more especially on the dissociation of $\mathrm{CO}_{2}$, remain answered. All simulation results have discrepancies when compared with shock-tube experiments, and no model is able to predict both the magnitude and temporal profile of the $\mathrm{CO}$ fourth positive system with satisfactory precision.

According to the preceding discussion, although radiation experiments have been widely conducted using OES, the thermodynamic models still need to be improved and validated. Radiation is attributed to excited states of species, whereas classical models deal with nonexcited species. Information on species densities, especially on ground-state populations, is also necessary. Unfortunately, most experiments have focused on emissions from the $\mathrm{CO}$ fourth positive system and have not obtained quantitative data for the $\mathrm{CO}$ number density, which is essential for determining an accurate rate coefficient of $\mathrm{CO}_{2}$. Consequently, the development of accurate quantitative diagnostic techniques for shock-tube experiments would be highly beneficial. Tunable diode laser absorption spectroscopy (TDLAS) is a powerful tool with which to probe atoms and molecules nonintrusively and has seen use in many areas such as combustion diagnostics, chemical sensing, and environment monitoring [18-20]. In contrast with other optical diagnostic applications, the ground state can be assessed. Our preliminary experiments illustrated the potential for using TDLAS to study high-temperature flows for entry into the Martian atmosphere [20]. However, the range of the measurement needs to be significantly improved; essentially, only one condition was studied, and only a few measurement points were quoted.

One part of this work completes the experimental database for simultaneously measuring gas temperature and $\mathrm{CO}$ number density distribution behind a strong shock wave in $\mathrm{CO}_{2}-\mathrm{N}_{2}$ mixture with two running conditions of initial pressure and velocity. Experiments are conducted in a hydrogen-oxygen combustion shock tube using an optical system based on OES and TDLAS. Rotational and vibrational temperatures are obtained by analyzing the high-temporal-resolution and high-spatial-resolution experimental spectra of the $\mathrm{CN}$ violet $\left(B^{2} \Sigma^{+} \rightarrow X^{2} \Sigma^{+}, \Delta v=0\right)$ system. Combined with the temperature results from $\mathrm{OES}$, the $\mathrm{CO}$ number density distribution in the thermal equilibrium zone is determined by a TDLAS system near $2335.778 \mathrm{~nm}$, with simultaneous calibration using the known position line near $2335.544 \mathrm{~nm}$ for a room-temperature reference cavity. Moreover, a kinetic code based on Park's two-temperature mechanism is developed for comparison with experiment and for studying the mechanism of $\mathrm{CO}_{2}$ dissociation for Mars atmosphere entry under the conditions considered in this work.

\section{Measurement Techniques}

\section{A. Optical Emission Spectroscopy}

OES is a useful method for measurements of high-temperature gas behind a strong shock wave and is widely adopted, as documented in the literature [21-23]. Here, only a brief description is presented to define our notations.

The emission intensity is described as

$$
I_{v^{\prime \prime}, J^{\prime \prime}}^{v^{\prime}, J^{\prime}}=N_{v^{\prime}, J^{\prime}} A_{v^{\prime \prime}, J^{\prime \prime}}^{v^{\prime}, J^{\prime}} h v_{v^{\prime \prime}, J^{\prime \prime}}^{v^{\prime}, J^{\prime}}
$$

where $\left(v^{\prime}, J^{\prime}\right)$ and $\left(v^{\prime \prime}, J^{\prime \prime}\right)$ represent the vibrational and rotational quantum numbers in the upper level and lower level, respectively; $N_{v^{\prime}, J^{\prime}}$ is the population in the upper level $\left(v^{\prime}, J^{\prime}\right) ; A_{v^{\prime \prime}, J^{\prime \prime}}^{v^{\prime}, J^{\prime}}$ is the Einstein transition probability; $h$ is the Planck constant; and $v_{v^{\prime \prime}, J^{\prime \prime}}^{v^{\prime}, J^{\prime}}$ is the transition frequency.

Assuming that the Born-Oppenheimer approximation and FranckCondon principle apply, the transition probability is expressed as

$$
A_{v^{\prime \prime}, J^{\prime \prime}}^{v^{\prime} J^{\prime}}=\frac{64 \pi^{4}\left(v_{v^{\prime \prime}, J^{\prime \prime}}^{v^{\prime}, J^{\prime}}\right)^{3} S_{J^{\prime \prime}}^{J^{\prime}}}{3 h\left(2 J^{\prime}+1\right)} q_{v^{\prime}, v^{\prime \prime}} R_{e}^{2}
$$

where $S_{J^{\prime \prime}}^{J^{\prime}}$ is the Hönl-London factor, $q_{v^{\prime}, v^{\prime \prime}}$ is the Franck-Condon factor, and $R_{e}^{2}$ is the average value of the electronic transition moment.
Assuming a Boltzmann distribution at each molecular state, fixing the values of $v^{\prime}$ and $v^{\prime \prime}$ and substituting Eq. (2) to Eq. (1), the emission intensity is described by

$$
I_{v^{\prime \prime}, J^{\prime \prime}}^{v^{\prime}, J^{\prime}} \propto\left(v_{v^{\prime \prime}, J^{\prime \prime}}^{v^{\prime}, J^{\prime}}\right)^{4} S_{J^{\prime \prime}}^{J^{\prime}} \exp \left(-\frac{F\left(v^{\prime}, J^{\prime}\right)}{k T_{r}}-\frac{G\left(v^{\prime}\right)}{k T_{v}}\right)
$$

where $k$ (joules per kelvin) is the Boltzmann constant, and $F\left(v^{\prime}, J^{\prime}\right)$ (in joules) and $G\left(v^{\prime}\right)$ (in joules) are the rotational and vibrational energies, respectively. Note that the rotational energy is also a function of the vibrational quantum number because of the coupling of rotation and vibration. According to Eq. (3), the relative emission intensity depends on the rotational temperature and vibrational temperature. Therefore, a spectral analysis, which compares a theoretical calculated spectrum with an experimental spectrum by an iterative process, is widely used for estimation of the rotational and vibrational temperature of high-temperature gas behind a strong shock wave.

The $\mathrm{CN}$ radical has been identified as the most appropriate molecule for temperature measurement during entries to Mars, which has a $\mathrm{CO}_{2} / \mathrm{N}_{2}$ atmosphere $[\underline{6}, \underline{8}, \underline{14}, 17,24,25]$. In previous work, we analyzed in detail the spectral structure of the $\mathrm{CN}$ violet system $\left(B^{2} \Sigma^{+} \rightarrow X^{2} \Sigma^{+}, \Delta v=0\right.$ sequence) and proposed a new rotational and vibrational temperature measurement method based on a highresolution spectrometer [26]. This method strongly depends on the accuracy of the calculated spectrum and the accurate calibration of the spectral resolution. Here, a brief description of the method is given. Figure 1 illustrates the distribution of the rotational lines of the $\mathrm{CN}$ violet system $\left(B^{2} \Sigma^{+} \rightarrow X^{2} \Sigma^{+}, \Delta v=0\right.$ sequence $)$ at $7000 \mathrm{~K}$ in thermal equilibrium, with each sequence of points representing an electronic-vibrational transition. The rectangular panel shows that the emission spectrum in the wavelength range $(387.6-388.6 \mathrm{~nm})$ is only composed of rotational lines of the $P$ branch for the $(0,0)$ transition (rotational number $J$ range from 0 to 57 ), i.e., the emission intensity in this range is only controlled by the rotational temperature. According to an accurate calibration of the spectral resolution, the rotational temperature can be determined through a precise analysis of the range (387.6-388.6 nm) of the $\mathrm{CN}$ violet system $\left(B^{2} \Sigma^{+} \rightarrow X^{2} \Sigma^{+}\right.$, $\Delta v=0$ sequence); this wavelength range corresponds to the $(0,0)$ transition of the $\mathrm{CN}$ violet system $\left(B^{2} \Sigma^{+} \rightarrow X^{2} \Sigma^{+}, \Delta v=0\right.$ sequence). The vibrational temperature is then estimated by minimizing the difference between the experimental and theoretical spectra in the whole wavelength range (376-390 nm). A more detailed description of this method including an error analysis is given in the literature [26].

\section{B. Tunable Diode Laser Absorption Spectroscopy}

The fundamental theoretical principle of TDLAS is also well understood $[27,28]$ and is reproduced here concisely. When a wellcollimated laser at frequency $v$ enters a gas sample, a proportion of the light is absorbed, and the fractional transmission is described by the Beer-Lambert law, expressed as

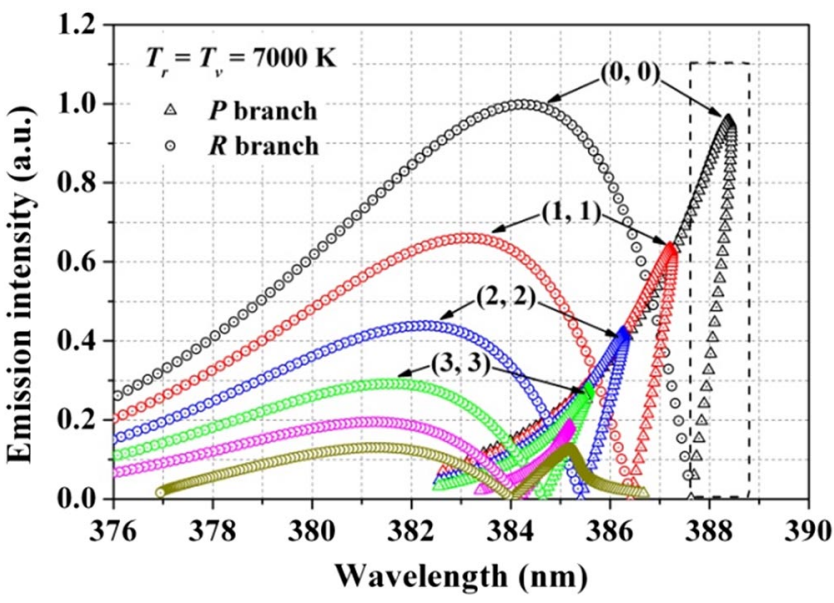

Fig. 1 Structure of rotational lines of the $\mathrm{CN}$ violet system at $7000 \mathrm{~K}$ in thermal equilibrium. 


$$
\left(\frac{I_{t}}{I_{0}}\right)_{v}=\exp \left(-\alpha_{v}\right)=\exp \left(-P_{i} \cdot S(T) \cdot \phi(v) \cdot L\right)
$$

where $I_{0}$ and $I_{t}$ are the incident and transmitted laser intensities, respectively; $\left(I_{t} / I_{0}\right)_{v}$ is the spectral transmittance; $\alpha_{v}$ is the spectral absorbance; $P_{i}$ (in standard atmospheres) is the partial pressure of the absorbing species ( $\mathrm{CO}$ in this work); $L$ (in centimeters) is the optical path in the gas, practically the inner diameter of the shock tube; $S(T)\left(\mathrm{cm}^{-2} \cdot \mathrm{atm}^{-1}\right)$ is the line strength; and $\phi(v)$ (in centimeters) is the line-shape function. The line strength $S(T)$ can be expressed in terms of the known line strength at a reference temperature $T_{0}[\underline{29}]$ :

$$
\begin{aligned}
& S(T)=S\left(T_{0}\right) \frac{Q\left(T_{0}\right)}{Q(T)}\left(\frac{T_{0}}{T}\right) \exp \left[-\left(\frac{h c}{k}\right)\left(E_{1}^{\prime \prime}-E_{2}^{\prime \prime}\right)\left(\frac{1}{T}-\frac{1}{T_{0}}\right)\right] \\
& \quad \times \frac{\left[1-\exp \left(-\left(h c v_{0} / k T\right)\right)\right]}{\left[1-\exp \left(-\left(h c v_{0} / k T_{0}\right)\right)\right]}
\end{aligned}
$$

where $h$ is Planck's constant; $k$ (in joules per Kelvin) is Boltzmann's constant; $c$ (in centimeters per second) is the speed of light; $E^{\prime \prime}$ is the lower-state energy; $v_{0}$ is the line-center frequency; $T_{0}$ (in kelvins) is the reference temperature (usually $296 \mathrm{~K}$ ); and $Q(T)$ is the partition function of the absorbing molecule $\mathrm{CO}$. Because the line-shape function $\phi(v)$ is normalized to unity, defined as

$$
\int \phi(v) \mathrm{d} v \equiv 1
$$

the integrated absorbance $A$ can be calculated by taking the frequency integral of the absorption line shape:

$$
A=\int \alpha_{v} \mathrm{~d} v=P_{C O} \cdot S(T) \cdot L
$$

According to Eq. (6), the absorbance at a specific transition is a function of the temperature and partial pressure of the absorbing species. Therefore, a measurement of absorbance at one carefully chosen transition can be used to infer the partial pressure of $\mathrm{CO}$ if the temperature is known. In this study, rotational and vibrational temperatures are obtained through time gating OES diagnostics with nanosecond temporal resolution.

According to the ideal gas law, the CO number density $n_{c o}$ can be deduced as

$$
\begin{aligned}
n_{C O} & =\frac{6.02 \times 10^{23} \cdot P_{C O}}{R \cdot T \cdot L}\left[\frac{101325 \cdot \mathrm{Pa}}{1 \cdot \mathrm{atm}} \frac{1 \cdot \mathrm{m}^{3}}{100^{3} \mathrm{~cm}^{3}}\right] \\
& =\frac{6.1 \times 10^{22} \cdot A}{R \cdot T \cdot S(T) \cdot L}\left[\mathrm{~cm}^{-3}\right]
\end{aligned}
$$

An important aspect of implementing TDLAS is the selection of optimal transitions; the transitions used in this study are given in Table 1. These transitions are selected according to spectroscopic parameters provided in the HITRAN 2008 database [30]. Absorption spectra near $2.33 \mu \mathrm{m}$ are calculated under experimental conditions in our work ( $T=7000 \mathrm{~K}, P=1 \mathrm{~atm}, L=7.8 \mathrm{~cm}, 17 \% \mathrm{CO})$, as shown in Fig. 2. The CO absorption line near $2335.778 \mathrm{~nm}\left(4281.228 \mathrm{~cm}^{-1}\right)$ is selected for two reasons. First, it provides absorption strength sufficient to ensure high sensitivity in the temperature range of interest in this work. Second, it can be conveniently verified by the absorption line near $2335.544 \mathrm{~nm}\left(4281.657 \mathrm{~cm}^{-1}\right)$, which can be easily calibrated by a Fabry-Perot interferometer and a $\mathrm{CO}$ reference cavity at room temperature. Conveniently, both transitions can be accessed by the same distributed feedback laser.

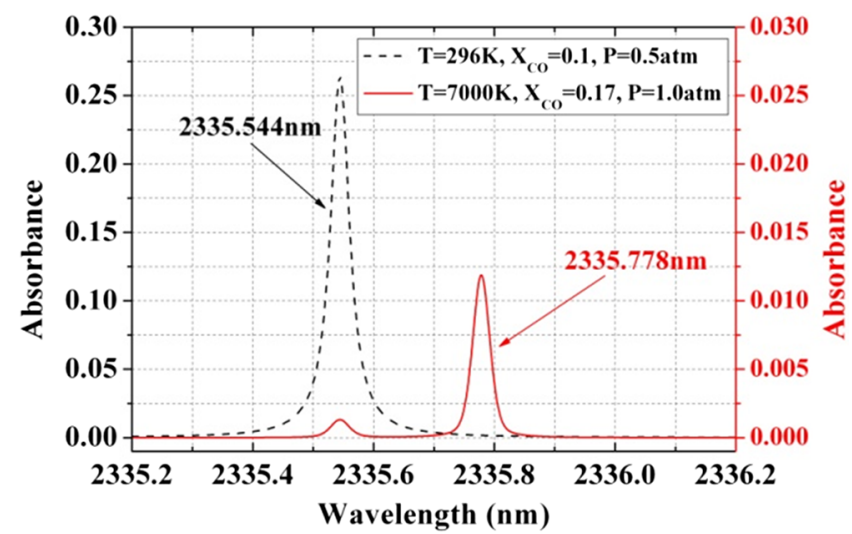

Fig. 2 Calculated spectra of $\mathrm{CO}$ absorption near $2.33 \mu \mathrm{m}$ for choosing appropriate CO transitions.

\section{Chemical Kinetic Calculations}

Chemical kinetic calculations are performed following the works of Park et al. [4] and Lee et al. [31]. Park et al.'s model [4] has been widely validated by various shock-tube experiments since 1994 $[\underline{3}, \underline{6}, \underline{31}]$. This model has also been extensively used to study nonequilibrium radiation for Mars entry $[\underline{8}, 14,32]$ and has served as a foundation in developing more precise models, such as threetemperature models and collisional-radiative models [16,17]. There are two reasons for choosing Park's model in our work. First, many published simulation results based on Park's model could help us to cross-check the accuracy of our simulation, and second, studying Park's model could offer insight before using more novel and sophisticated models in our future work.

In the present work, the calculation is initialized using the perfect gas shock jump conditions (Rankine-Hugoniot equations) based on the known driven gas $T, p_{i}$, chemical composition, and the measured shock velocity $V_{s}$. The thermochemical state of the gas is assumed frozen immediately behind the shock wave to initialize the first point in the postshock region. The downstream nonequilibrium reacting flow is then computed by solving one-dimensional Euler equations. The kinetic code developed in our work is based on Park's twotemperature model (rotational/translational temperature $T_{r}$, vibrational/electronic temperature $T_{v}$ ). In this model, the translational temperature is assumed to be equated to the rotational temperature $T_{r}$, whereas the electronic temperature is equated to the vibrational temperature $T_{v}$. To simplify the calculations, a separate electron temperature $T_{e}$ is not considered, and $T_{e}$ is instead assumed equal to vibrational temperature $T_{v}$ because inelastic collisions between electrons and molecules are mainly responsible for vibrational excitation [33]. Vibrational energy relaxation is modeled using a Landau-Teller formulation, where relaxation times are determined in accordance with a Millikan-White approximation formula [34] combined with Park corrections [35]. Details of the thermal nonequilibrium modeling used in this code are described in [4]. The effect of vibrational relaxation on the chemical kinetics is also considered in the model. Although $\mathrm{CO}_{2}$ is a triatomic molecule, its molecular structure is linear and symmetric, and its vibrational degrees of freedom are similar with that of the diatomic molecules. To simplify calculations, $\mathrm{CO}_{2}$ molecules are taken into account as diatomic molecules in the numerical modeling.

The model includes 29 reactions and 14 chemical species: $\mathrm{C}, \mathrm{O}, \mathrm{N}$, $\mathrm{CO}, \mathrm{C}_{2}, \mathrm{~N}_{2}, \mathrm{CN}, \mathrm{NO}, \mathrm{O}_{2}, \mathrm{CO}_{2}, \mathrm{C}^{+}, \mathrm{NO}^{+}, \mathrm{NCO}$, and $\mathrm{e}^{-}$. A summary of chemical reactions and reactions rates is given in Table 2. The table shows that the chemical reaction rate is determined using the Arrhenius-type form

Table 1 Spectroscopic line parameters used in the current study

\begin{tabular}{lcccc}
\hline \hline Transitions & Wavelength $\lambda, \mathrm{nm}$ & Frequency $v_{0}, \mathrm{~cm}^{-1}$ & Line strength $S$ at $296 \mathrm{~K}, \mathrm{~atm}^{-1} \cdot \mathrm{cm}^{-2}$ & $\mathrm{Low}_{-\mathrm{state}}$ energy $E^{\prime \prime}, \mathrm{cm}^{-1}$ \\
\hline 1 & 2335.544 & 4281.657 & $7.916 \times 10^{-2}$ & 57.670 \\
2 & 2335.778 & 4281.228 & $1.483 \times 10^{-7}$ & 3378.954 \\
\hline \hline
\end{tabular}


Table 2 Reaction rate coefficients for the Martian atmosphere in the present model

\begin{tabular}{|c|c|c|c|c|c|c|c|}
\hline & Reaction & $M$ & $T_{x}$ & $C, \mathrm{~cm}^{3} \cdot \mathrm{mol}^{-1} \cdot \mathrm{s}^{-1}$ & $n$ & $T_{d}$ & Source \\
\hline & & & & Dissociation & & & \\
\hline 1) & $\mathrm{C}_{2}+\mathrm{M} \rightarrow \mathrm{C}+\mathrm{C}+\mathrm{M}$ & All & $T_{a}$ & $1.5 \times 10^{16}$ & 0.00 & 71,600 & Gökçen [36] \\
\hline \multirow[t]{3}{*}{ 2) } & $\mathrm{N}_{2}+\mathrm{M} \rightarrow \mathrm{N}+\mathrm{N}+\mathrm{M}$ & -- & $T_{a}$ & $7.0 \times 10^{21}$ & -1.60 & 113,200 & Park et al. [4] \\
\hline & & $\mathrm{C}, \mathrm{O}, \mathrm{N}$ & -1 & $3.0 \times 10^{22}$ & -- & -- & Park et al. [4] \\
\hline & & $\mathrm{e}^{-}$ & - & $3.0 \times 10^{24}$ & -- & - & Gökçen [36] \\
\hline \multirow[t]{2}{*}{ 3) } & $\mathrm{O}_{2}+\mathrm{M} \rightarrow \mathrm{O}+\mathrm{O}+\mathrm{M}$ & -- & $T_{a}$ & $2.0 \times 10^{21}$ & -1.50 & 59,750 & Park et al. [4] \\
\hline & & $\mathrm{C}, \mathrm{O}, \mathrm{N}$ & -- & $1.0 \times 10^{22}$ & -- & -- & Park et al. $[\overline{4}]$ \\
\hline 4) & $\mathrm{CN}+\mathrm{M} \rightarrow \mathrm{C}+\mathrm{N}+\mathrm{M}$ & All & $T_{a}$ & $2.53 \times 10^{14}$ & 0.00 & 71,000 & Gökçen [3] $]$ \\
\hline \multirow[t]{2}{*}{ 5) } & $\mathrm{CO}+\mathrm{M} \rightarrow \mathrm{C}+\mathrm{O}+\mathrm{M}$ & -- & $T_{a}$ & $2.3 \times 10^{20}$ & -1.00 & 129,000 & Park et al. [4] \\
\hline & & $\mathrm{C}, \mathrm{O}, \mathrm{N}$ & - & $3.4 \times 10^{20}$ & -- & -- & Park et al. $[\overline{4}]$ \\
\hline \multirow[t]{3}{*}{ 6) } & $\mathrm{NO}+\mathrm{M} \rightarrow \mathrm{N}+\mathrm{O}+\mathrm{M}$ & -1 & $T_{a}$ & $5.0 \times 10^{15}$ & 0.00 & 75,500 & Park et al. $[\overline{4}]$ \\
\hline & & $\mathrm{N}_{2}$ & -- & $1.45 \times 10^{15}$ & -- & 74,700 & Park et al. [4] \\
\hline & & $\mathrm{CO}_{2}$ & -- & $2.41 \times 10^{15}$ & -- & -- & Park et al. $[\overline{4}]$ \\
\hline \multirow[t]{2}{*}{ 7) } & $\mathrm{CO}_{2}+\mathrm{M} \rightarrow \mathrm{CO}+\mathrm{O}+\mathrm{M}$ & -2 & $T_{a}$ & $6.9 \times 10^{21}$ & -1.5 & 63,275 & Park et al. $[\overline{4}]$ \\
\hline & & $\mathrm{C}, \mathrm{O}, \mathrm{N}$ & -- & $1.4 \times 10^{22}$ & -- & -- & Park et al. $[\overline{4}]$ \\
\hline \multirow[t]{2}{*}{ 8) } & $\mathrm{NCO}+\mathrm{M} \rightarrow \mathrm{CO}+\mathrm{N}+\mathrm{M}$ & All & $T_{a}$ & $6.3 \times 10^{16}$ & -0.5 & 24,000 & Park et al. $[\underline{4}]$ \\
\hline & & & & exchange & & & \\
\hline 9) & $\mathrm{N}_{2}+\mathrm{O} \rightarrow \mathrm{NO}+\mathrm{N}$ & -- & $T_{r}$ & $6.4 \times 10^{17}$ & -1.00 & 38,370 & Park et al. [4] \\
\hline 10) & $\mathrm{NO}+\mathrm{O} \rightarrow \mathrm{O}_{2}+\mathrm{N}$ & -- & $T_{r}$ & $8.4 \times 10^{12}$ & 0.00 & 19,450 & Park et al. $[\overline{4}]$ \\
\hline 11) & $\mathrm{CO}+\mathrm{C} \rightarrow \mathrm{C}_{2}+\mathrm{O}$ & -- & $T_{r}$ & $2.0 \times 10^{17}$ & -1.00 & 58,000 & Park et al. [ 4$]$ \\
\hline 12) & $\mathrm{CO}+\mathrm{O} \rightarrow \mathrm{O}_{2}+\mathrm{C}$ & -- & $T_{r}$ & $3.9 \times 10^{13}$ & -0.18 & 69,200 & Park et al. [u] \\
\hline 13) & $\mathrm{CO}+\mathrm{N} \rightarrow \mathrm{CN}+\mathrm{O}$ & $-\ldots$ & $T_{r}$ & $1.0 \times 10^{14}$ & 0.00 & 38,600 & Park et al. $[\overline{4}]$ \\
\hline 14) & $\mathrm{N}_{2}+\mathrm{C} \rightarrow \mathrm{CN}+\mathrm{N}$ & -- & $T_{r}$ & $5.24 \times 10^{13}$ & 0.00 & 22,600 & Gökçen [36] \\
\hline 15) & $\mathrm{CN}+\mathrm{O} \rightarrow \mathrm{NO}+\mathrm{C}$ & -- & $T_{r}$ & $1.6 \times 10^{13}$ & 0.10 & 14,600 & Park et al. [4] \\
\hline 16) & $\mathrm{CN}+\mathrm{C} \rightarrow \mathrm{C}_{2}+\mathrm{N}$ & -- & $T_{r}$ & $5.0 \times 10^{13}$ & 0.00 & 13,000 & Park et al. [4] \\
\hline 17) & $\mathrm{CO}+\mathrm{CO} \rightarrow \mathrm{C}+\mathrm{CO}_{2}$ & -- & $T_{r}$ & $2.3 \times 10^{9}$ & 0.50 & 65,710 & Losev and Chernyi [37] \\
\hline 18) & $\mathrm{CO}_{2}+\mathrm{O} \rightarrow \mathrm{CO}+\mathrm{O}_{2}$ & -- & $T_{r}$ & $2.1 \times 10^{13}$ & 0.00 & 27,800 & Park et al. [4] \\
\hline 19) & $\mathrm{N}_{2}+\mathrm{C}_{2} \rightarrow \mathrm{CN}+\mathrm{CN}$ & -- & $T_{r}$ & $1.5 \times 10^{13}$ & 0.00 & 21,000 & Gökçen [3] $]$ \\
\hline 20) & $\mathrm{CO}+\mathrm{NO} \rightarrow \mathrm{NCO}+\mathrm{O}$ & -- & $T_{r}$ & $3.8 \times 10^{17}$ & -0.873 & 51,600 & Park et al. [4] \\
\hline 21) & $\mathrm{CN}+\mathrm{O}_{2} \rightarrow \mathrm{NCO}+\mathrm{O}$ & -- & $T_{r}$ & $6.6 \times 10^{12}$ & 0.00 & -200 & Park et al. [4] \\
\hline 22) & $\mathrm{CN}+\mathrm{CO}_{2} \rightarrow \mathrm{NCO}+\mathrm{CO}$ & $-\ldots$ & $T_{r}$ & $4.0 \times 10^{14}$ & 0.00 & 19,200 & Park et al. $[\overline{4}]$ \\
\hline 23) & $\mathrm{CN}+\mathrm{NO} \rightarrow \mathrm{NCO}+\mathrm{N}$ & -- & $T_{r}$ & $1.0 \times 10^{14}$ & 0.00 & 21,200 & Park et al. $[\overline{4}]$ \\
\hline 24) & $\mathrm{CN}+\mathrm{CO} \rightarrow \mathrm{NCO}+\mathrm{C}$ & -- & $T_{r}$ & $1.5 \times 10^{16}$ & -0.487 & 65,800 & Park et al. $[\overline{4}]$ \\
\hline 25) & $\mathrm{CO}+\mathrm{N} \rightarrow \mathrm{NO}+\mathrm{C}$ & $-\ldots$ & $T_{r}$ & $2.9 \times 10^{11}$ & 0.50 & 53,630 & Losev and Chernyi [37] \\
\hline \multirow[t]{2}{*}{ 26) } & $\mathrm{NO}+\mathrm{CO} \rightarrow \mathrm{CO}_{2}+\mathrm{N}$ & -- & $T_{r}$ & $4.6 \times 10^{8}$ & 0.50 & 12,070 & Losev and Chernyi [37] \\
\hline & & & & harge exchange & & & \\
\hline \multirow[t]{2}{*}{ 27) } & $\mathrm{NO}^{+}+\mathrm{C} \rightarrow \mathrm{NO}+\mathrm{C}^{+}$ & -- & $T_{r}$ & $1.0 \times 10^{13}$ & 0.00 & 23,200 & Park et al. [4] \\
\hline & & & & Ionization & & & \\
\hline 28) & $\mathrm{O}+\mathrm{N} \rightarrow \mathrm{NO}^{+}+\mathrm{e}^{-}$ & -- & $T_{r}$ & $8.8 \times 10^{8}$ & 1.00 & 31,900 & Park et al. [4] \\
\hline 29) & $\mathrm{C}+\mathrm{e}^{-} \rightarrow \mathrm{C}^{+}+\mathrm{e}^{-}+\mathrm{e}^{-}$ & -- & $T_{v}$ & $3.9 \times 10^{33}$ & -3.78 & 130,700 & Park et al. $[\overline{4}]$ \\
\hline
\end{tabular}

$$
k_{f}=C T_{x}^{n} \exp \left(-T_{d} / T_{x}\right)
$$

where $T_{x}$ is the temperature controlling the reaction and is assumed to be a function of the geometric average temperature $T_{a}=\sqrt{T_{r} T_{v}}$ for all dissociation reactions. The reaction-rate coefficients $C, n$, and $T_{d}$ are obtained from the work of Park et al. [4], Gökçen [36], and Losev and Chernyi [37]. The backward rate coefficient is evaluated from the equilibrium constant based on the principle of microreversibility $[\underline{38,39]}$ :

$$
k_{b}\left(T_{b}\right)=k_{f}\left(T_{b}\right) / K^{e q}\left(T_{b}\right)
$$

The equilibrium constant is estimated by taking the minimized Gibbs free energy approach in this work.

\section{Experimental Apparatus}

The experimental setup for quantitative measurement of temperature and $\mathrm{CO}$ number density in the simulated Mars atmosphere behind strong shock waves is illustrated in Fig. 3 . As shown in the figure, the experimental investigations were conducted in a hydrogen-oxygen combustion shock-tube facility. The shock tube was an $8.5-\mathrm{m}$-long facility comprising two sections (i.e., driver and driven sections), initially separated by an aluminum diaphragm (having thickness of $2 \mathrm{~mm}$ ). The driver section had an inner diameter of $84 \mathrm{~mm}$, and the driven shock tube had an inner diameter of $78 \mathrm{~mm}$. Using combustionproduct gases at high pressure as the driver gases, a strong shock wave that passes through the stagnant test gas could be easily acquired. The shock velocity was determined by three ion probes along the driven tube and by measuring the times of arrival of the shock wave. The variation of the velocity in these experiments did not exceed $1.3 \%$. The shock tube was equipped with optical accessible quartz windows whose transmission region ranged 200-3000 nm. Experiments were carried out in a mixture of $70 \% \mathrm{CO}_{2}$ and $30 \% \mathrm{~N}_{2}$. Although this composition differs from the exact composition of the Mars atmosphere, such a ratio allows a better $\mathrm{CN}$ radical emission signal-tonoise ratio (SNR) while retaining the same chemical kinetics processes. On the basis of previous experiments, two initial pressure/ shock velocity conditions were investigated: $p_{i}=100 \mathrm{~Pa}$ and $V_{s}=7.09 \pm 0.05 \mathrm{~km} / \mathrm{s}$ (called the low-pressure condition) and $p_{i}=300 \mathrm{~Pa}$ and $V_{s}=5.68 \pm 0.07 \mathrm{~km} / \mathrm{s}$ (called the high-pressure condition).

Figure 3 also gives an overview of the optical diagnostic system, which consists of an OES system and a TDLAS system. The OES system was designed to collect the $\mathrm{CN}$ violet system radiation emitted from the high-temperature test gas behind the strong shock wave. The emission was collected through a $250 \mathrm{~mm}$ focal length quartz lens installed in front of an optical fiber. The optical path was perpendicular to the flow axis, and the field of view was less than $1 \mathrm{~mm}$ in diameter and $1 \mathrm{~mm}$ in depth. Emission spectra were recorded using an Andor SR-500i spectrograph having a focal length of $500 \mathrm{~mm}$. Although this spectrometer allowed switching between three different gratings, our experiments used only a $1200 \mathrm{~g} / \mathrm{mm}$ grating blazed at $300 \mathrm{~nm}$. The spectrometer was equipped with an Andor DH-740 gated intensified charge-coupled device camera with 


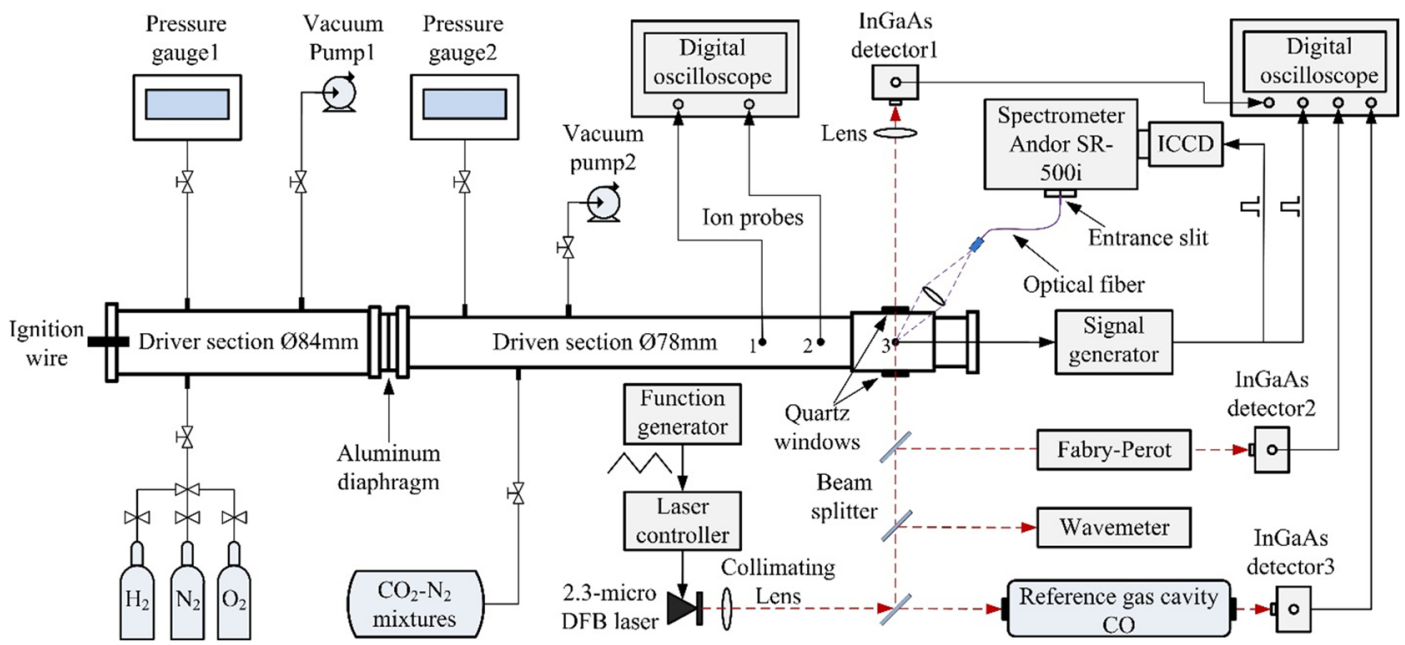

Fig. 3 Schematic diagram of the experimental setup. Note that the optical path for OES is perpendicular to the flow axis, though it is denoted otherwise in the figure.

$2048 \times 512$ pixels. The camera exposure time was set to $30 \mathrm{~ns}$, which is short enough to "freeze" the shock image within the spectral capture field. The entrance slit was fixed at $100 \mu \mathrm{m}$ to get an acceptable SNR and sufficient spectral resolution. Using a narrowline-width diode laser (central wavelength of $777.19 \mathrm{~nm}$, line width $\Delta \lambda<0.001 \mathrm{~nm}$ ), the spectral resolution was measured as $0.154 \mathrm{~nm}$ with a Lorentz profile. The acquired spectra were calibrated in terms of the relative intensity in the ultraviolet range (below $400 \mathrm{~nm}$ ) using a National Institute of Standards and Technology traceable quartztungsten-halogen standard reference lamp (Oriel, model 63945). Alignment of the spectrometer, alignment of the calibration source, and visualization of the observation location were achieved with a visible $\mathrm{He}-\mathrm{Ne}$ laser.

For the TDLAS system, a distributed feedback laser (Nanoplus $\mathrm{GmbH}$ ) produced $\sim 30 \mathrm{~mW}$ of stable output power near $2.33 \mu \mathrm{m}$. The laser wavelength and intensity were controlled by a commercial temperature and current controller (Thorlabs, model ITC-502). Scanned-wavelength direct absorption was used in the present study. The injection current of the laser controller was modulated by a triangular ramp signal from a function generator (Tektronix, model AFG-3101) so that the lasing wavelength scanned a spectral range of $0.7 \mathrm{~nm}$ to probe $\mathrm{CO}$ absorption transitions as shown in Table 1 . The wavelength was modulated at a repetition rate of $50 \mathrm{kHz}(20 \bar{\mu}$ s per single cycle, two absorption features per scan). Such high-frequency scanning allows for sufficient temporal resolution of absorption measurements. To calibrate and monitor the wavelength of the diode laser simultaneously, the laser beam was separated by two beam splitters. One laser beam traveled through a room-temperature reference cavity for absolute wavelength calibration, whereas the other beam traveled through a Fabry-Perot interferometer (Thorlabs, model SA200-18B) having a $1.5 \mathrm{GHz}$ free spectral range for relative wavelength calibration. The laser signals were sensed simultaneously by three InGaAs detectors (Thorlabs, model PDA10D) and recorded by an oscilloscope (Tektronix Inc., model DPO4034) at a sampling rate of $100 \mathrm{MHz}$.

The OES and TDLAS systems were triggered synchronously by the output signal of ion probe 3 through a signal generator (Stanford Research System, model DG535) when the shock wave neared the ion probe. In addition, although only one single emission spectrum and two absorption features could be acquired during a shot, the signal generator could also be used to control the delay time and thus record different moments for detailed measurement in the nonequilibrium, or equilibrium, region.

\section{Results and Discussions}

\section{A. Determination of Rotational and Vibrational Temperatures}

In our previous work, the spectral structure of the $\mathrm{CN}$ violet system $\left(B^{2} \Sigma^{+} \rightarrow X^{2} \Sigma^{+}, \Delta v=0\right.$ sequence) was thoroughly investigated, and a theoretical synthetic spectrum was calculated on the basis of our spectral resolution [26]. The spectral resolution was $0.154 \mathrm{~nm}$ with a Lorentz profile. At such high spectral resolution, the slight effect of other rotational lines tends to be neglected for the wavelength range of 387.6-388.6 $\mathrm{nm}$ (rotational number $J$ ranging from 0 to 57 ), and the rotational temperature measurement has sufficient precision even though the fine structure of the rotational lines cannot be observed. Conversely, the vibrational structure of the $\mathrm{CN}$ violet band system $\left(B^{2} \Sigma^{+} \rightarrow X^{2} \Sigma^{+}, \Delta v=0\right.$ sequence $)$ is apparent, and the vibrational temperature is estimated by minimizing the difference (i.e., error) between the experimental and theoretical spectrum. The spectral resolution is also taken as a free parameter with which to evaluate the temperature error due to the measurement uncertainty, and the value obtained by the minimization method agrees with the experimental value. A dimensionless quantity $E r$ is used in our study to evaluate the degree of difference between the experimental and theoretical synthetic spectra [24], which is defined as

$$
E r=\frac{\left(I_{\mathrm{cal}}(\lambda)-I_{\mathrm{exp}}(\lambda)\right)^{2}}{\left(I_{\mathrm{exp}}(\lambda)\right)^{2}}
$$

The temporal behavior of the $\mathrm{CN}$ violet system $\left(B^{2} \Sigma^{+} \rightarrow X^{2} \Sigma^{+}\right.$, $\Delta v=0$ sequence) behind strong shock waves was observed through OES. Figure 4 compares experimental spectra with theoretical synthetic spectra for the low-pressure condition at different delay times. The solid lines represent the experimental spectra of the $\mathrm{CN}$ violet system. The dashed lines represent the corresponding theoretical synthetic spectra when rotational and vibrational temperatures are fixed at optimum values. $E r$ in the top panel of Fig. 4 a indicates excellent agreement between the theoretical synthetic and experimental spectra in the wavelength range of $387.6-388.6 \mathrm{~nm}$, meaning that a reasonable rotational temperature is achieved. For wavelengths in the range of $376-385 \mathrm{~nm}$ (the tail region of the $\mathrm{CN}$ violet system), however, there is obvious discrepancy between the theoretical and experimental spectra, which indicates that higher lying rotational lines do not follow a Boltzmann distribution. However, the vibrational temperature determination can maintain satisfactory precision. This is because the broad tail of the spectrum has a relatively small influence on the determination of the vibrational temperature, owing to the much lowerenergy quotient in high $J$ rotational line states compared with the energy quotient in low $J$ rotational line states. As shown in Figs. $4 \mathrm{a}$ and $4 \mathrm{~b}$, the rotational temperature is higher than the vibrational temperature at the beginning, and the shock-heated gas is obviously in a thermal nonequilibrium state. In the quasi-equilibrium and equilibrium region, as shown in Figs. 4c, 4d, the theoretical synthetic and experimental spectra match well, and the equilibrium temperature is found to be equal to $7000 \pm 400 \mathrm{~K}$. According to the fitting procedure, the average uncertainty is $1000 \mathrm{~K}$ in nonequilibrium and $400 \mathrm{~K}$ in equilibrium for both temperatures. The accuracy of our experiments is fairly good and is 

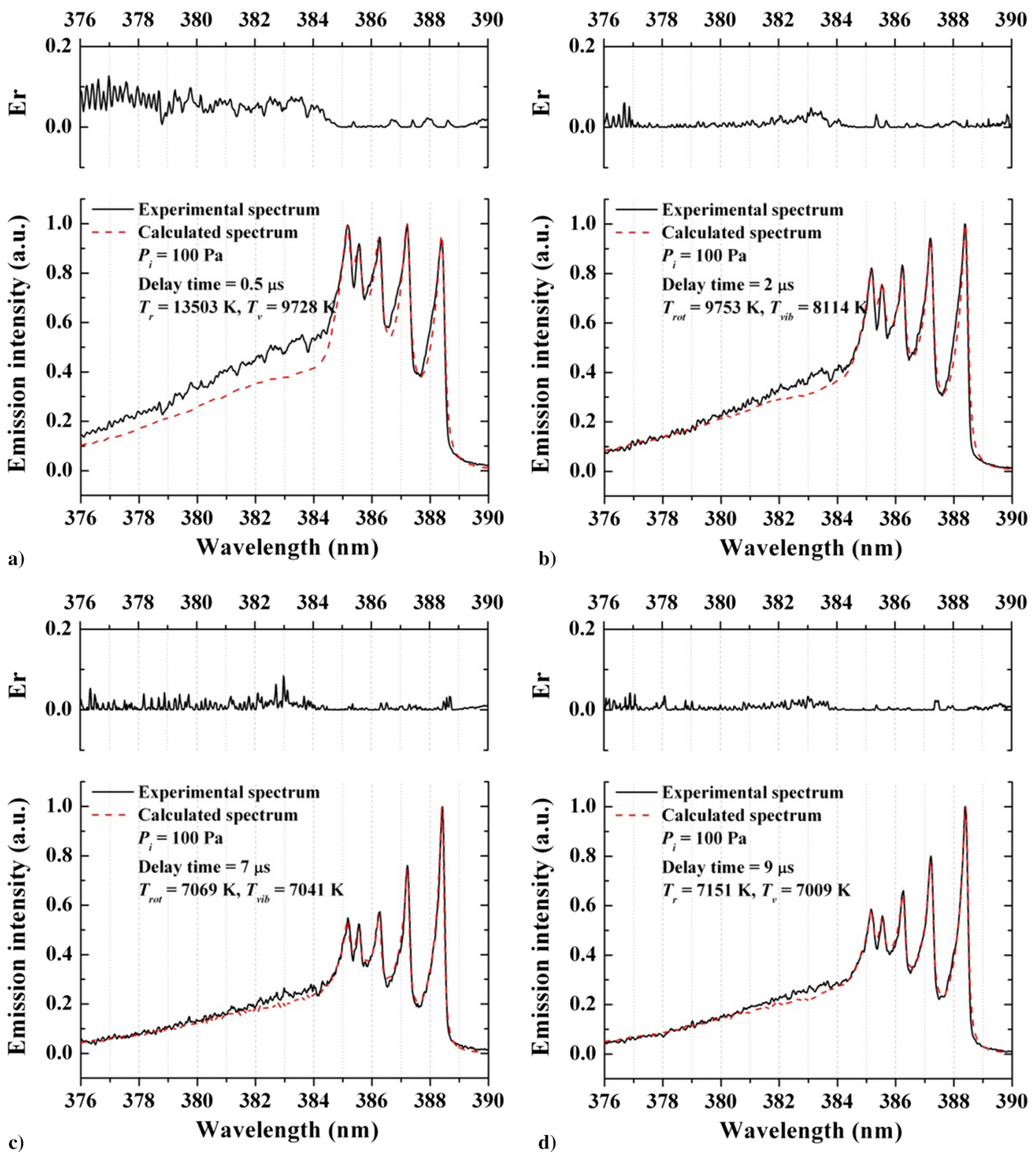

Fig. 4 Experimental and theoretical synthetic spectra of the $\mathrm{CN}$ violet system $(\Delta v=0)$ at different delay times (experiment: $p_{i}=100 \mathrm{~Pa}$, $V_{s}=7.09 \pm 0.05 \mathrm{~km} / \mathrm{s}$; composition: $70 \% \mathrm{CO}_{2}$ and $30 \% \mathrm{~N}_{2}$ ).

similar to that of results obtained by other researchers using OES [24,40]. A detailed uncertainty analysis from theoretical spectrum calculation and spectral resolution measurement was described in our previous work $[20,26]$. The same analysis is used for the high-pressure condition, and the temperature results are presented in Fig. 5. The equilibrium temperature is about $6100 \pm 300 \mathrm{~K}$, and average uncertainty of about $300 \mathrm{~K}$ is acquired.

Figure 6 presents temporal profiles of the temperatures behind the shock waves for the two initial experimental conditions, wherein each temperature point is deduced by the precise analysis of time gating spectral of the $\mathrm{CN}$ violet system $\left(B^{2} \Sigma^{+} \rightarrow X^{2} \Sigma^{+}, \Delta v=0\right.$ sequence). To record the overall spectra of the nonequilibrium and equilibrium regions, the OES system was triggered each $100 \mathrm{~ns}$ when the shock-heated gas was considered in the nonequilibrium region and each $1 \mu \mathrm{s}$ when equilibrium was assumed. Figure $\underline{6}$ presents a comparison for the two conditions. It is important to note that there are discrepancies between the two conditions. These discrepancies mainly include the rate of the temperature rise behind the shock wave, the nonequilibrium effects, and the decay rate of the temperature following the peak location. We believe that different shock velocities are the main reason resulting in the obvious temperature difference of the two tests in this paper. However, the temperature profile with the initial pressure of $100 \mathrm{~Pa}$, especially the equilibrium temperature, seemed very close to those of the $200 \mathrm{~Pa}$ case in our previous experiments [20]. Reasons for this anomalous phenomenon are not fully understood, and more systematic studies including theoretic work will be necessary.

For the low-pressure condition in this study, both the rotational temperature and vibrational temperature rise quickly with relatively large uncertainty, and the rate of the rotational temperature rise is higher than that of the vibrational temperature. A nonequilibrium peak is evident from the profile. Afterward, owing to the high-speed collisions between gaseous particles, thermal equilibrium between the rotational states and vibrational states is reached. As shown in Fig. 6, there is good agreement between the rotational temperature and vibrational temperature, and the equilibrium temperature is constant with distance behind the shock wave. The experimental data reveal that the shock-heated gas should reach thermal equilibrium at a delay time of about $6 \mu \mathrm{s}$.

However, there are no obvious distinctions between the rotational and vibrational temperatures for the high-pressure condition, even at the initial time behind the shock wave. The rotational and vibrational temperatures have a similar increase and decrease and finally reach a steady state. According to experimental results, we can assume that 

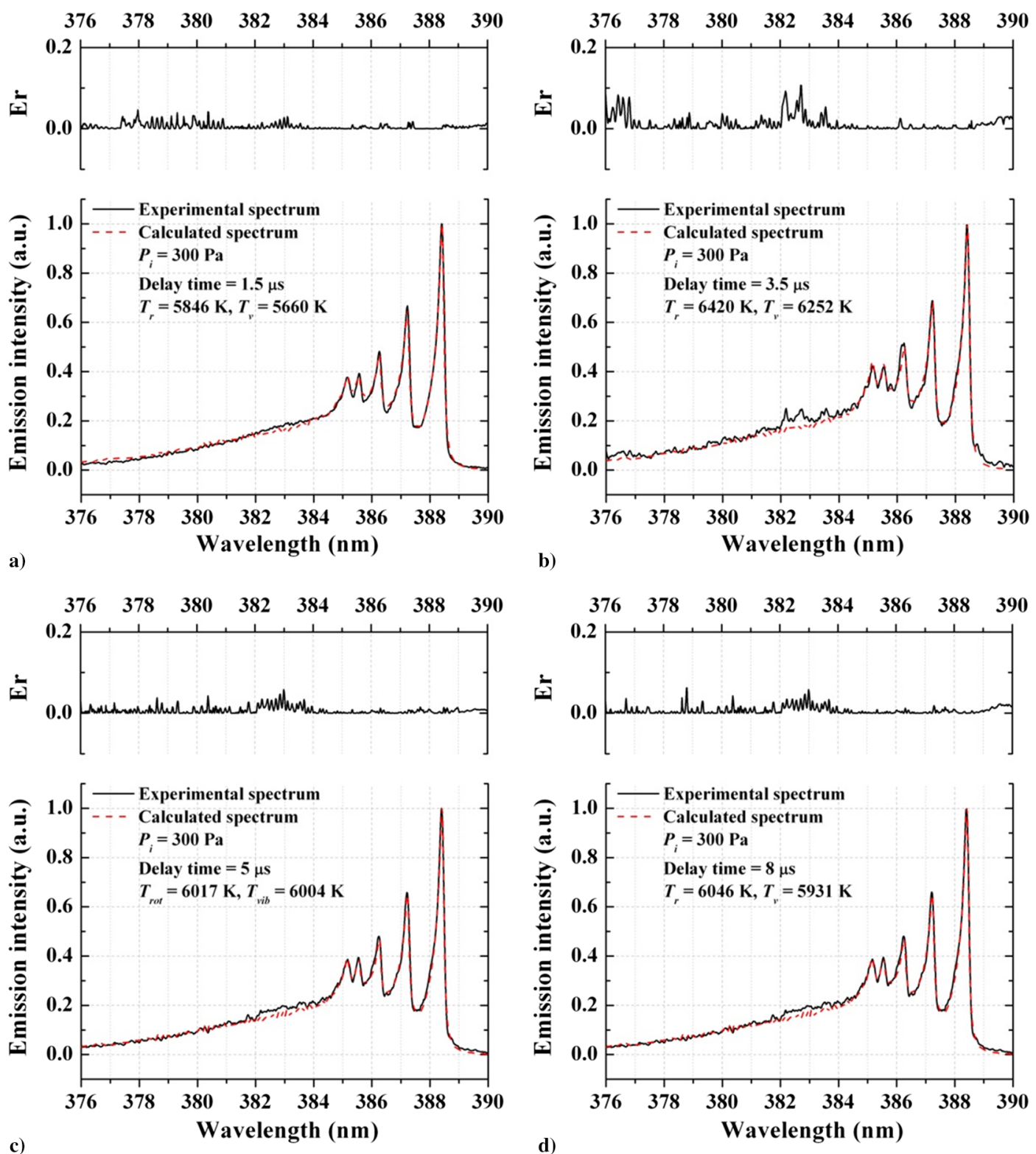

Fig. 5 Experimental and theoretical synthetic spectra of the $\mathrm{CN}$ violet system $(\Delta v=0)$ at different delay times (experiment: $p_{i}=300$ Pa, $V_{s}=5.68 \pm 0.07 \mathrm{~km} / \mathrm{s}$; composition: $70 \% \mathrm{CO}_{2}$ and $30 \% \mathrm{~N}_{2}$ ).

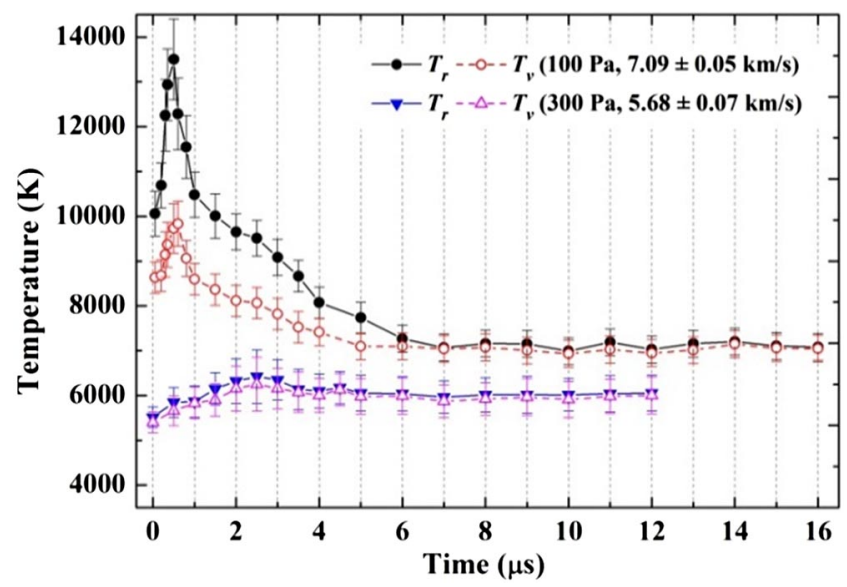

Fig. 6 Time evolutions of rotational and vibrational temperatures behind the shock waves for the two initial pressure conditions (composition: $70 \% \mathrm{CO}_{2}$ and $30 \% \mathrm{~N}_{2}$ ). the relaxation time of equilibration between the rotational and vibrational state of $\mathrm{CN}$ is short and is expected to be shorter than the temporal resolution ( $30 \mathrm{~ns}$ ) of the OES system. There are two possible reasons for such differences. On the one hand, the vibrational excitation is not completely due to a higher pressure (meaning fewer nonequilibrium effects) and a lower speed (meaning lower temperature). The characteristic time scale of the vibrational relaxation of $\mathrm{CN}$ may be comparable to that of the rotational state for the high-pressure condition. On the other hand, a higher pressure increases the rate of collision between particles, which induces a sufficiently fast relaxation between the rotational state and vibrational state. As shown in Fig. $\underline{6}$, the shock-heated gas should reach thermal equilibrium at a delay time of about $5 \mu \mathrm{s}$.

\section{B. Carbon-Monoxide Absorption Measurements Behind the Strong Shock Wave}

Whereas optical emission spectroscopy gives information about excited states of the studied species, diode-laser absorption spectroscopy is related to the ground and low-energy states and is 


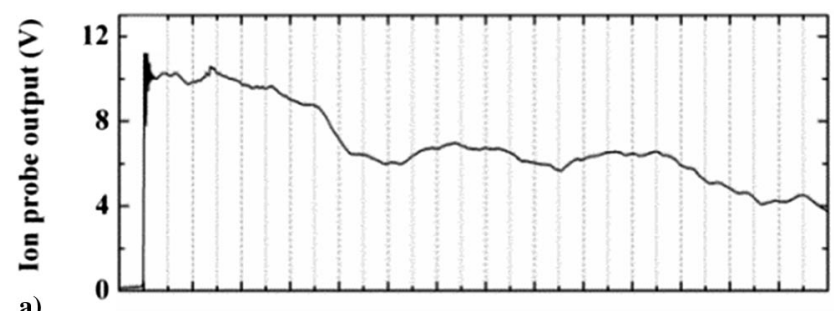

a)

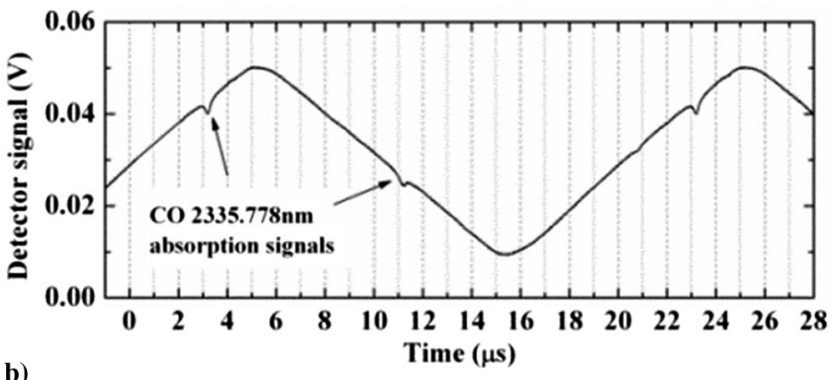

Fig. 7 Raw experimental data for the region behind a strong shock wave under the high-pressure conditions: a) output signal of ion probe 3 , and b) detected absorbance signals.

especially interesting in terms of the determination of ground-state populations. Figure 7 presents a typical absorption measurement signal behind a shock wave during one shot under the high-pressure condition. In Fig. 7a, a sharp rising of probe 3 indicates the arrival of the incident shock at the location of the probe. Figure $7 \mathrm{~b}$ shows a direct-absorption scan using the TDLAS system, where the laser intensity changes in response to an injection current ramp.

To obtain the integrated absorbance of the $\mathrm{CO}$ absorption line near $2335.778 \mathrm{~nm}$, the data processing includes three steps. First, for each measured absorbance signal as shown in Fig. $\underline{7 b}$, a polynomial is fitted to the nonabsorbing wings of the absorption feature to extrapolate a zero-absorption baseline. Here, the baseline is fitted with a fifth-order polynomial. Second, an absorbance plot of the absorption feature can be constructed according to the baseline obtained in the first step. A Voigt profile is used to fit the absorbance plot in this study. The bottom panel of Fig. 8 shows an experimental absorption line shape fitted with the Voigt profile, whereas the top portion shows the fitting residual, which is less than $1 \%$ of the peak absorption throughout the line profile. Such a low fitting residual illustrates that a high SNR is achieved in this work. Third, the integrated absorbance can be calculated by taking the frequency
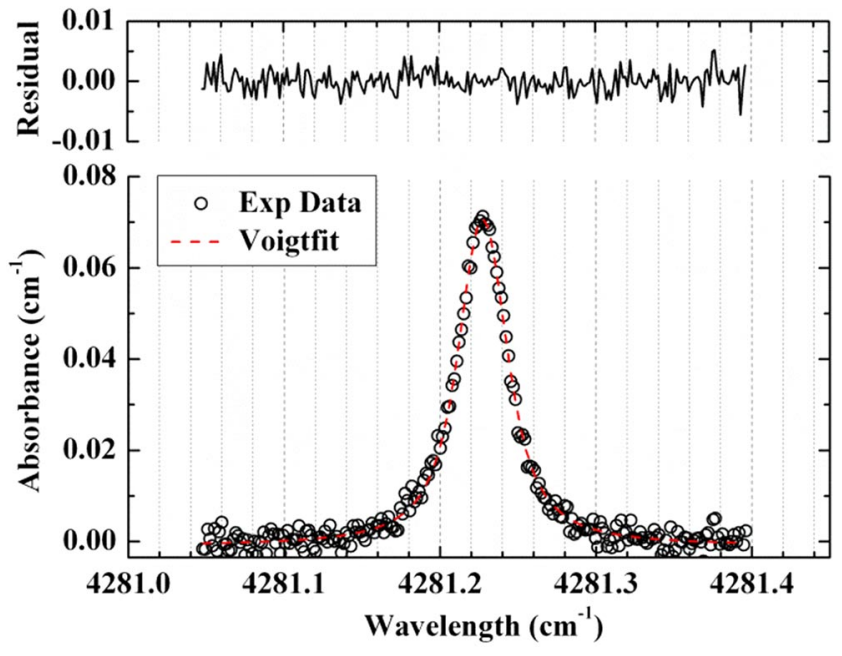

Fig. 8 Single-scan absorption data for measurement of the $\mathrm{CO}$ number density in a hydrogen-oxygen combustion-driven shock tube with the $\mathrm{CO}$ transition near $2335.778 \mathrm{~nm}$. integral of the whole absorption line shape. Combined with these temperature results from OES, the CO number density in the thermal equilibrium region can be determined using Eq. (7).

Figure 9 presents the evolutions of integrated absorbance along the temperature distributions behind the shock waves obtained using TDLAS. The figure shows that fluctuation of the integrated absorbance of $\mathrm{CO}$ is very slight in the thermal equilibrium region, and the variation tendency of the absorbance is consistent with the temperature results. It is considered that chemical reactions in the high-temperature gas have also achieved equilibrium after 6 and $5 \mu \mathrm{s}$ in the low- and highpressure conditions, respectively. Therefore, the deduced average $\mathrm{CO}$ number densities in the low- and high-pressure conditions are $2.91 \times 10^{17}$ and $1.01 \times 10^{18} \mathrm{~cm}^{-3}$, corresponding to equilibrium temperatures of $7000 \pm 400$ and $6100 \pm 300 \mathrm{~K}$. The integrated absorbance of $\mathrm{CO}$ in the nonequilibrium region can also be determined by TDLAS. However, this absorbance cannot be used to infer the $\mathrm{CO}$ number density because the $\mathrm{CO}$ number density in the nonequilibrium region does not follow the Boltzmann distribution in the ground state, and the intense thermochemical reactions occurring in the nonequilibrium region lead to many uncertain factors.

According to Eq. (7), uncertainty in the $\mathrm{CO}$ number density consists of uncertainty in the temperature measurement, uncertainty in the path length, uncertainty in the integrated absorbance, and uncertainty in the line-strength calculation. A temperature uncertainty of around $6 \%$ is acquired by OES. The thickness of the boundary is less than $0.8 \mathrm{~mm}$ in our experiments according to the calculation methods of Mirels [41]. The calculated result shows that the uncertainty in path length $L$ is about $1 \%$. The uncertainty in the integrated absorbance is mainly caused by the error associated with the baseline and Voigt profile fit. As shown in Fig. 8, the high SNR of the baseline and Voigt profile fit results in uncertainty of $\sim 1 \%$ in the integrated absorbance. The uncertainty in the line strength is also determined by the uncertainty in the temperature measurement, and a $5 \%$ uncertainty in the temperature measurement causes a $\sim 7 \%$ line-strength calculation error in our experimental temperature range. The overall uncertainty in the $\mathrm{CO}$ number density is therefore about $15 \%$. However, the method of calculating the line strength has not been verified for such a high-temperature environment. The reliability of the line-strength uncertainty assessment needs to be validated, and line-strength calibration experiments using a shock tube are necessary, which will be the subject of our future work.

\section{Comparisons with Chemical Kinetic Calculations}

Temperature and species densities evolutions obtained by this model are presented in Figs. 10 and 11 . The kinetic code developed in this work is based on the Park's two-temperature model. In this model, it is assumed that the high-temperature gas immediately behind the shock wave is in vibrational nonequilibrium. The existence of the vibrational relaxation time causes a significant difference between the rotational temperature and the vibrational temperature in the calculations.

Figures 10 and 11 compare numerical calculations and experimental results for the low- and high-pressure conditions, respectively. As shown in Figs. 10a and 11a, equilibrium temperature calculations are in good agreement with experiments for the two conditions. However, significant temperature discrepancies exist in the nonequilibrium region. The numerical calculations overestimate the rotational and vibrational temperatures measured by OES in the first microseconds. For the low-pressure condition, there are also obvious discrepancies in the first $0.5 \mu \mathrm{s}$, namely during the induction or incubation period behind the shock wave. The two-temperature model predicts a decrease in the rotational temperature and an increase in the vibrational temperature due to vibration-translation exchange, and the rotational temperature can reach $20,000 \mathrm{~K}$ or even higher. Inconsistent with this, according to the OES results, both the rotational temperature and vibrational temperature keep increasing in the first $0.5 \mu \mathrm{s}$, and the maximum rotational temperature is less than $14,000 \mathrm{~K}$. As shown in Fig. 11a, these discrepancies are more obvious in the high-pressure condition when the nonequilibrium effects are weak. Several reasons can explain such differences. From a theoretical standpoint, the model is not accurate enough to describe the 


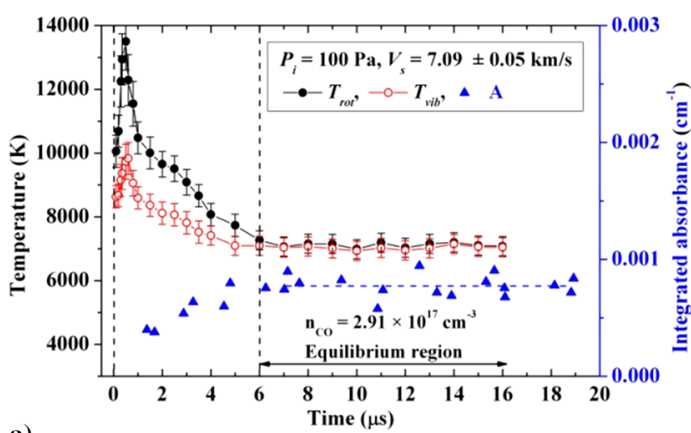

a)

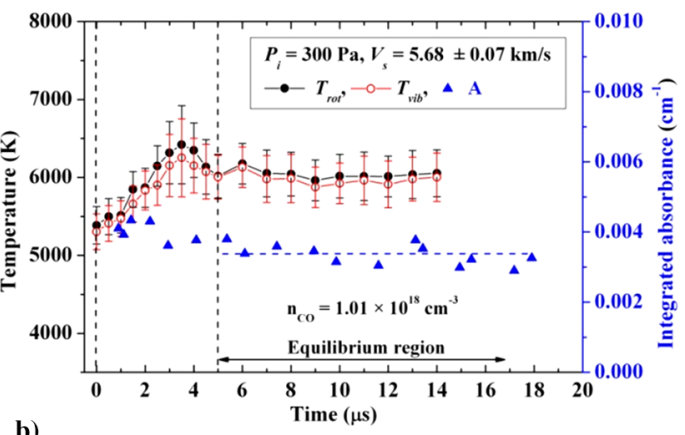

b)

Fig. 9 Evolution of the $\mathrm{CO}$ integrated absorbance and temperatures behind the shock wave under the two initial conditions.
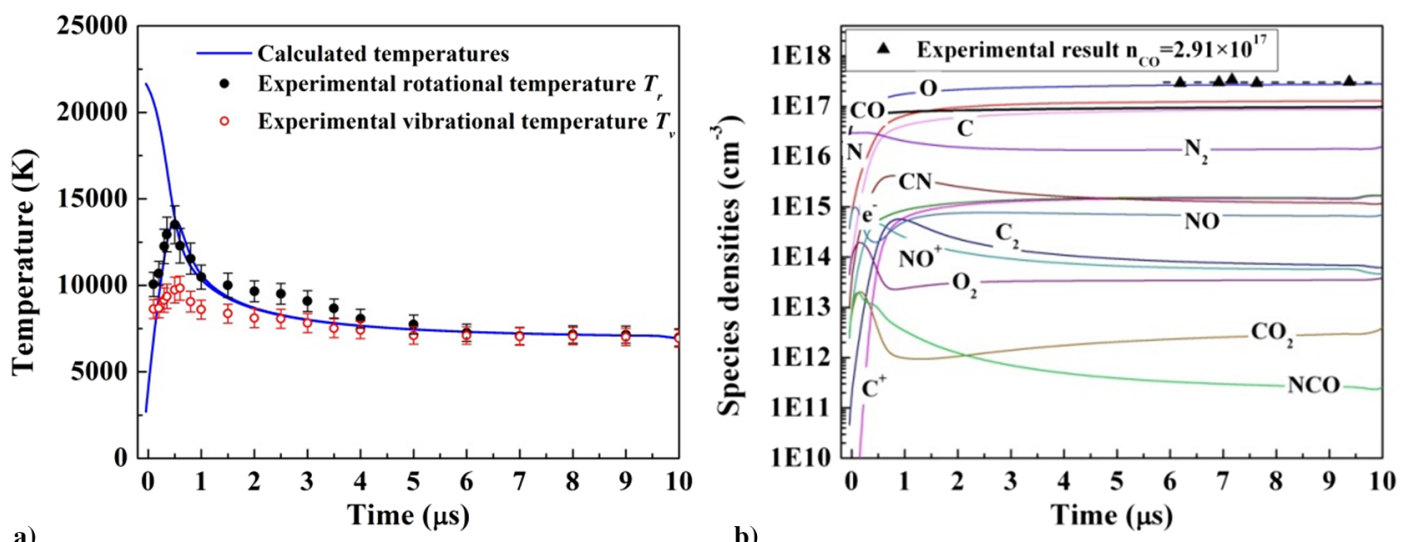

Fig. 10 Comparison of the modeling results with measurements for the low-pressure condition $\left(70 \% \mathrm{CO}_{2}-30 \% \mathrm{~N}_{2}, p_{i}=100 \mathrm{~Pa}, V_{s}=7.09 \mathrm{~km} / \mathrm{s}\right)$.
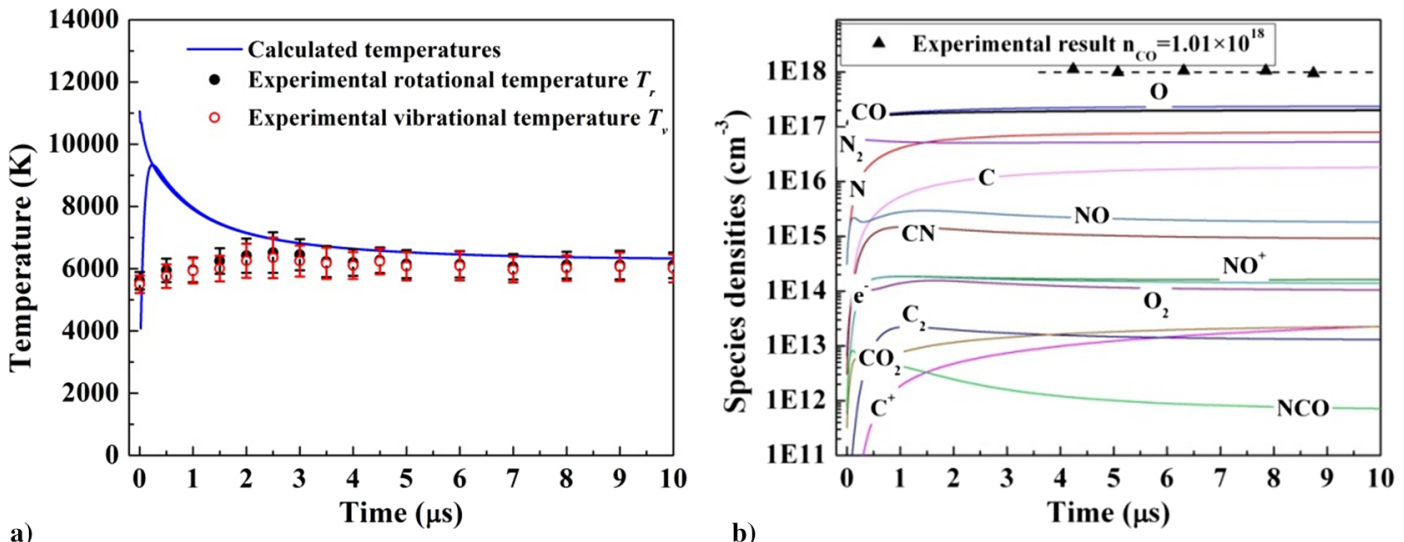

Fig. 11 Comparison of the modeling results with measurements for the high-pressure condition $\left(70 \% \mathrm{CO}_{2}-30 \% \mathrm{~N}_{2}, p_{i}=300 \mathrm{~Pa}, V_{s}=5.68 \mathrm{~km} / \mathrm{s}\right)$.

nonequilibrium processes because of inaccurate chemical kinetic rate coefficients, the invalid hypothesis of the Boltzmann distribution, the effect of the optical thickness, and the limitations of perfect-gas shock jump conditions derived from Rankine-Hugoniot equations. From an experimental standpoint, sources of error in the nonequilibrium region immediately behind the shock wave include light reflection from the inner wall of the shock tube, optical distortion along the line of sight, the effect of precursory ionization of the shocked gas, and underestimation of the self-absorption intensity. Comparisons reveal several differences and a lack of understanding related to fundamental physics and experimental details.

The deduced CO number densities are also compared with the calculated temporal profiles in Figs. $10 \mathrm{~b}$ and $11 \mathrm{~b}$. It is clear from the figures that the experimental results in the thermal equilibrium region are higher than calculations for the two experimental conditions. There are two potential reasons for this discrepancy. One relates to the uncertainties in temperature results obtained from OES. Obviously, temperature is the dominant thermodynamic parameter not only determining the calculation of the $\mathrm{CO}$ number density but also affecting the accuracy of the line-strength calculation. Owing to heat conduction between the high-temperature gas and the shock tube, there is a radial thermal gradient in the flowfield, and the temperature on the centerline should be higher than that at the edge. As described earlier, the measurement volume obtained by OES is located near the centerline of the shock tube, and the volume is less than $1 \mathrm{~mm}$ in diameter. According to thermodynamic equilibrium calculations, a $10 \%$ variation in temperature can create a $\sim 40 \%$ variation in $\mathrm{CO}$ number density in the temperature range of interest $(5000-8000 \mathrm{~K})$ [42]. Therefore, the temperature uncertainties due to the nonuniformity of the flowfield and measurement error may affect the number density 
calculation based on Eq. (7). The other reason for the discrepancy is the limitation of the method used in the calculations of the absorption line strength, as discussed in Sec. V.B. Although the calculated results (e.g., line strength and line position) of the two selected transitions are in excellent agreement with the HITRAN database in the temperature range of 70-3000 $\mathrm{K}$ [43], the previous calculation method may not be applicable and needs to be verified at higher temperatures, especially in the considered high-temperature environment $(T \geq 6000 \mathrm{~K})$.

A general comparison of experimental results with a simple twotemperature calculation shows that experiment techniques need to be improved to increase the accuracy of temperature and density measurements. The combination of the OES technique with the Abelinversion method to determine the radial variation of the temperature is a direction of future development. In parallel, to improve the spatial solution of TDLAS, a new method called tunable diode laser absorption tomography (TDLAT) should be developed. TDLAT is capable of determining two-dimensional spatially resolved distribution of species density by combining TDLAS with computed tomography. A quantitative measurement of ground-state densities of atomic oxygen using laser absorption is also necessary. Furthermore, the comparison reveals that experiments need more complex modeling, such as a numerical model taking into account the coupling between kinetics and radiation.

\section{Conclusions}

The CO number density distribution behind a strong shock wave was investigated in the simulation of Martian atmosphere entry processes by coupling optical emission spectroscopy and tunable diode laser absorption spectroscopy (TDLAS). Experiments were carried out in a hydrogen-oxygen combustion-driven shock tube with a $\mathrm{CO}_{2}-\mathrm{N}_{2}$ (70:30) mixture and with two sets of initial conditions (100 Pa, $7.09 \pm 0.05 \mathrm{~km} / \mathrm{s} ; 300 \mathrm{~Pa}, 5.68 \pm 0.07 \mathrm{~km} / \mathrm{s})$. Timeresolved emission spectroscopy allowed to analyze the time evolution of the $\mathrm{CN}$ violet system $\left(B^{2} \Sigma^{+} \rightarrow X^{2} \Sigma^{+}, \Delta v=0\right.$ sequence) and rotational and vibrational temperatures between the shock and the thermochemical equilibrium region. Nonequilibrium effects were clearly much weaker at higher pressure. Meanwhile, a TDLAS system was constructed and demonstrated to provide accurate and temporally resolved CO number density diagnostics in conditions relevant to Mars entry. Two CO absorption lines near $2.33 \mu \mathrm{m}$ were selected for detecting the $\mathrm{CO}$ number density and were simultaneously monitored and calibrated using a room-temperature reference cavity and a Fabry-Perot interferometer. An uncertainty analysis was performed to assess the measurement uncertainties in the temperature and $\mathrm{CO}$ number density. A numerical code, based on Park's two-temperature theory, was developed to reproduce the temperature and $\mathrm{CO}$ number density behind the shock wave. These computations show that the simple numerical model is not accurate enough to describe the experimental results, and a more detailed model is needed. Suggestions for improving the experimental accuracy and kinetic model were proposed.

This work completes the authors' previous work and illustrates the feasibility of a TDLAS system for species number density measurements in conditions relevant to Mars entry. These results will be useful in understanding mechanisms of $\mathrm{CO}_{2}$ dissociation and providing verification data of ground-state densities for the study of chemical kinetic processes occurring in the shock layer. In addition, the absorption measurements of $\mathrm{CO}$ are important in the development and validation of the spectroscopic database for high-temperature $(T \geq 3000 \mathrm{~K})$ environments.

\section{Acknowledgments}

This work was funded in part by the National Natural Science Foundation of China. We would like to thank Hongbo Lu, Junming Lv, and Jinlong Peng, who work at China Academy of Aerospace Aerodynamics, for proving advice for simulation and modeling. We also thank Fei Yu from the University of Bath for his valuable comments to improve the paper.

\section{References}

[1] Grinstead, J. H., Wright, M. J., Bogdanoff, D. W., and Allen, G. A., "Shock Radiation Measurements for Mars Aerocapture Radiative Heating Analysis," Journal of Thermophysics and Heat Transfer, Vol. 23, No. 2, 2009, pp. 249-255.

doi: $10.2514 / 1.37281$

[2] Wright, M. J., Beck, R. A. S., Edquist, K. T., Driver, D., Sepka, S. A., Slimko, E. M., and Willcockson, W. H., "Sizing and Margins Assessment of Mars Science Laboratory Aeroshell Thermal Protection System," Journal of Spacecraft and Rockets, Vol. 51, No. 4, 2014, pp. 1125-1138. doi:10.2514/1.A32579

[3] Potter, D. F., Eichmann, T., Brandis, A., Morgan, R. G., Jacobs, P. A., and McIntyre, T. J., "Simulation of Radiating $\mathrm{CO}_{2}-\mathrm{N}_{2}$ Shock Layer Experiments at Hyperbolic Entry Conditions," 40th Thermophysics Conference, AIAA Paper 2008-3933, June 2008.

[4] Park, C., Howe, J. T., Jaffe, R. L., and Candler, G. V., "Review of Chemical-Kinetic Problems of Future NASA Missions, II: Mars Entries," Journal of Thermophysics and Heat Transfer, Vol. 8, No. 1, 1994, pp. 9-23. doi: $10.2514 / 3.496$

[5] Brandis, A. M., Johnston, C. O., Cruden, B. A., Prabhu, D. K., Wrayd, A. A., Liu, Y., Schwenke, D. W., and Bose, D., "Validation of CO 4th Positive Radiation for Mars Entry," Journal of Quantitative Spectroscopy \& Radiative Transfer, Vol. 121, May 2013, pp. 91-104. doi:10.1016/j.jgstt.2013.02.009

[6] Rond, C., Boubert, P., Félio, J.-M., and Chikhaoui, A., "Nonequilibrium Radiation Behind a Strong Shock Wave in $\mathrm{CO}_{2}-\mathrm{N}_{2}$," Chemical Physics, Vol. 340, Nos. 1-3, 2007, pp. 93-104. doi:10.1016/j.chemphys.2007.08.003

[7] Marynowski, T., Löhle, S., and Fasoulas, S., "Two-Photon Absorption Laser-Induced Fluorescence Investigation of $\mathrm{CO}_{2}$ Plasmas for Mars Entry," Journal of Thermophysics and Heat Transfer, Vol. 28, No. 3, 2014, pp. 394-400. doi:10.2514/1.T4223

[8] Dikalyuk, A. S., Surzhikov, S. T., Kozlov, P. V., Shatalov, O. P., and Romanenko, Y. V., "Nonequilibrium Spectral Radiation Behind the Shock Waves in Martian and Earth Atmospheres," 44th AIAA Thermophysics Conference, AIAA Paper 2013-2505, 2013.

[9] Cruden, B. A., Prabhu, D., and Martinez, R., "Absolute Radiation Measurement in Venus and Mars Entry Conditions," Journal of Spacecraft and Rockets, Vol. 49, No. 6, 2012, pp. 1069-1079. doi:10.2514/1.A32204

[10] Gorelov, V. A., Gladyshev, M. K., Kireev, A. Y., and Shilenkov, S. V., "Nonequilibrium Ionization Behind a Strong Shock Wave in the Mars Atmosphere," Journal of Applied Mechanics and Technical Physics, Vol. 41, No. 6, 2000, pp. 970-976. doi:10.1023/A:1026681901051

[11] Brandis, A. M., Morgan, R. G., and McIntyre, T. J., "Analysis of Nonequilibrium CN Radiation Encountered During Titan Atmospheric Entry," Journal of Thermophysics and Heat Transfer, Vol. 25, No. 4, 2011, pp. 493-499. doi: $10.2514 / 1.50966$

[12] Takayanagi, H., and Fujita, K., "Absolute Radiation Measurements Behind Strong Shock Wave in Carbon Dioxide Flow for Mars Aerocapture Missions," 43rd AIAA Thermophysics Conference, AIAA Paper 2012-2744, June 2012.

[13] Rond, C., Bultel, A., Boubert, P., and Chéron, B. G., "Spectroscopic Measurements of Nonequilibrium $\mathrm{CO}_{2}$ Plasma in RF Torch," Chemical Physics, Vol. 354, Nos. 1-3, 2008, pp. 16-26. doi:10.1016/j.chemphys.2008.09.006

[14] Boubert, P., and Rond, C., "Nonequilibrium Radiation in Shocked Martian Mixtures," Journal of Thermophysics and Heat Transfer, Vol. 24, No. 1, 2010, pp. 40-49. doi: $10.2514 / 1.45385$

[15] Park, C., et al., "Problems of Rate Chemistry in the Flight Regimes of Aeroassisted Orbital Transfer Vehicles," 19th Thermophysics Conference, AIAA Paper 1984-1730, 1984.

[16] Rond, C., and Boubert, P., "Chemical Kinetic and Radiative Simulations for Titan Atmospheric Entry," Journal of Thermophysics and Heat Transfer, Vol. 23, No. 1, 2009, pp. 72-82. doi:10.2514/1.36918

[17] Bose, D., Wright, M. J., Bogdanoff, D. W., Raiche, G. A., and Allen, G. A., "Modeling and Experimental Assessment of CN Radiation Behind a Strong Shock Wave," Journal of Thermophysics and Heat Transfer, Vol. 20, No. 2, 2006, pp. 220-230. doi:10.2514/1.16869

[18] Li, F., Yu, X. L., Gu, H. B., Li, Z., Zhao, Y., Ma, L., Chen, L. H., and Chang, X. Y., "Simultaneous Measurements of Multiple Flow 
Parameters for Scramjet Characterization Using Tunable DiodeLaser Sensors," Applied Optics, Vol. 50, No. 36, 2011, pp. 6697-6707.

doi:10.1364/AO.50.006697

[19] Chao, X., Jeffries, J. B., and Hanson, R. K., "Absorption Sensor for $\mathrm{CO}$ in Combustion Gases Using 2.3 um Tunable Diode Lasers," Measurement Science and Technology, Vol. 20, No. 11, 2009, Paper 115201. doi:10.1088/0957-0233/20/11/115201

[20] Lin, X., Yu, X. L., Li, F., Zhang, S. H., Xin, J. G., and Chang, X. Y., "CO Concentration and Temperature Measurements in a Shock Tube for Martian Mixtures by Coupling OES and TDLAS," Applied Physics B: Lasers and Optics, Vol. 110, No. 3, 2012, pp. 401-409. doi:10.1007/s00340-012-5269-1

[21] Laux, C. O., "Optical Diagnostics and Radiative Emission of Air Plasmas," Ph.D. Thesis, Stanford Univ., Stanford, CA, 1993.

[22] Laux, C. O., Spence, T. G., Kruger, C. H., and Zare, R. N., "Optical Diagnostics of Atmospheric Pressure Air Plasmas," Plasma Sources Science and Technology, Vol. 12, No. 2, 2003, pp. 125-138. doi:10.1088/0963-0252/12/2/301

[23] Cipullo, A., Filippis, F. D., and Zeni, L., "Temperature Measurements of Air Plasma Flow Using Optical Emission Spectroscopy," Journal of Thermophysics and Heat Transfer, Vol. 25, No. 3, 2011, pp. 354-360. doi:10.2514/1.49305

[24] Kurosawa, K., Sugita, S., Fujita, K., Ishibashi, K., Kadono, T., Ohno, S., and Matsui, T., "Rotational-Temperature Measurements of Chemically Reacting CN Using Band-Tail Spectra," Journal of Thermophysics and Heat Transfer, Vol. 23, No. 3, 2009, pp. 463-472. doi: $10.2514 / 1.40037$

[25] Ram, R. S., Davis, S. P., Wallace, L., Engleman, R., Appadoo, D. R. T., and Bernath, P. F., "Fourier Transform Emission Spectroscopy of the $B^{2} \Sigma^{+}-X^{2} \Sigma^{+}$System of CN," Journal of Molecular Spectroscopy, Vol. 237, No. 2, 2006, pp. 225-231. doi:10.1016/j.jms.2006.03.016

[26] Lin, X., Yu, X. L., Li, F., Zhang, S. H., Xin, J. G., and Chang, X. Y., "Measurements of Nonequilibrium and Equilibrium Temperature Behind a Strong Shock Wave in Simulated Martian Atmosphere," Acta Mechanica Sinica, Vol. 28, No. 5, 2012, pp. 1296-1302. doi:10.1007/s10409-012-0104-9

[27] Spearrin, R. M., Jeffries, J. B., and Hanson, R. K., "Mid-Infrared Absorption Sensor for Measurements of $\mathrm{CO}$ and $\mathrm{CO}_{2}$ in Propulsion Flows," 52nd Aerospace Sciences Meeting, AIAA Paper 2014-0390, 2014.

[28] Schultz, I. A., Goldenstein, C. S., Spearrin, R. M., Jeffries, J. B., Hanson, R. K., Rockwell, R. D., and Goyne, C. P., "Multispecies Midinfrared Absorption Measurements in a Hydrocarbon-Fueled Scramjet Combustor," Journal of Propulsion and Power, Vol. 30, No. 6, 2014, pp. 1595-1604. doi:10.2514/1.B35261

[29] Zhou, X., "Diode-Laser Absorption Sensors for Combustion Control," Ph.D. Thesis, Stanford Univ., Stanford, CA, 2005.
[30] Rothman, L. S., et al., "The HITRAN 2008 Molecular Spectroscopic Database," Journal of Quantitative Spectroscopy \& Radiative Transfer, Vol. 110, Nos. 9-10, 2009, pp. 533-572. doi:10.1016/j.jgsrt.2009.02.013

[31] Lee, E. S., Park, C., and Chang, K. S., "Shock Tube Determination of CN Formation Rate in a CO- $\mathrm{N}_{2}$ Mixture," Journal of Thermophysics and Heat Transfer, Vol. 21, No. 1, 2007, pp. 50-56. doi:10.2514/1.25144

[32] Brandis, A. M., Johnston, C. O., Cruden, B. A., and Prabhu, D. K., "Investigation of Nonequilibrium Radiation for Mars Entry," 51st AIAA Aerospace Sciences Meeting, AIAA Paper 2013-1055, Jan. 2013.

[33] Jaffe, R. L., "Rate Constants for Chemical Reactions in HighTemperature Non-Equilibrium Air," AIAA 20th Thermophysics Conference, AIAA Paper 1985-1038, June 1985.

[34] Millikan, R. C., and White, D. R., "Systematics of Vibrational Relaxation," Journal of Chemical Physics, Vol. 39, No. 12, 1963, pp. 3209-3213. doi:10.1063/1.1734182

[35] Park, C., Nonequilibrium Hypersonic Aerothermodynamics, Wiley, New York, 1990, pp. 106-111.

[36] Gökçen, T., " $\mathrm{N}_{2}-\mathrm{CH}_{4}-\mathrm{Ar}$ Chemical Kinetic Model for Simulations of Atmospheric Entry to Titan," Journal of Thermophysics and Heat Transfer, Vol. 21, No. 1, 2007, pp. 9-18. doi: $10.2514 / 1.22095$

[37] Losev, S. A., and Chernyi, G. G., "Development of Thermal Protection System for Interplanetary Flight," Research Inst. of Mechanics, Rept. 036-96, Moscow State Univ., 1999.

[38] Gordon, S., and McBride, B. J., "Computer Program for Calculation of Complex Chemical Equilibrium Compositions and Applications," NASA RP 1311, 1994.

[39] Mcbride, B. J., Zehe, M. J., and Gordon, S., "NASA Glenn Coefficients for Calculating Thermodynamic Properties of Individual Species," NASA TP-2002-211556, 2002.

[40] Rond, C., Boubert, P., Félio, J.-M., and Chikhaoui, A., "Radiation Measurements in a Shock Tube for Titan Mixtures," Journal of Thermophysics and Heat Transfer, Vol. 21, No. 3, 2007, pp. 638-646. doi: $10.2514 / 1.28422$

[41] Mirels, H., "Turbulent Boundary Layer Behind Constant Velocity Shock Including Wall Blowing Effects," AIAA Journal, Vol. 22, No. 8, 1984, pp. 1042-1047. doi: $10.2514 / 3.8736$

[42] Babou, Y., Rivière, P., Perrin, M. Y., and Soufiani, A., "Spectroscopic Study of Microwave Plasmas of $\mathrm{CO}_{2}$ and $\mathrm{CO}_{2}-\mathrm{N}_{2}$ Mixtures at Atmospheric Pressure," Plasma Sources Science and Technology, Vol. 17, No. 4, 2008, Paper 045010. doi:10.1088/0963-0252/17/4/045010

[43] Tashkun, S. A., Perevalov, V. I., Teffo, J. L., Bykov, A. D., and Lavrentieva, N. N., "CDSD-1000, the High-Temperature Carbon Dioxide Spectroscopic Databank," Journal of Quantitative Spectroscopy \& Radiative Transfer, Vol. 82, Nos. 1-4, 2003, pp. 165-196. doi:10.1016/S0022-4073(03)00152-3 